\section{(6) OPEN ACCESS}

\title{
The safety of morphine use in acute coronary syndrome: a meta-analysis
}

\author{
Rugheed Ghadban, ${ }^{1}$ Tariq Enezate, ${ }^{\oplus 1}$ Joshua Payne, ${ }^{1}$ Haytham Allaham, ${ }^{2}$ \\ Ahmad Halawa, ${ }^{1}$ Hee Kong Fong, ${ }^{2}$ Obai Abdullah, ${ }^{1}$ Kul Aggarwal ${ }^{1}$
}

- Additional material is published online only. To view please visit the journal online (http://dx.doi.org/10.1136/ heartasia-2018-011142).

${ }^{1}$ Division of Cardiology, Department of Internal Medicine, University of Missouri, Columbia, Missouri, USA ${ }^{2}$ Department of Internal Medicine, University of Missouri, Columbia, Missouri, USA

Correspondence to Dr Tariq Enezate, Division of Cardiology, Department of Internal Medicine, University of Missouri, Columbia, MI 65211 USA; enezatet@health.missouri. edu

Received 5 November 2018 Revised 12 January 2019 Accepted 15 February 2019

\section{Check for updates}

(C) Author(s) (or their employer(s)) 2019. Re-use permitted under CC BY-NC. No commercial re-use. See rights and permissions. Published by BMJ.

\begin{tabular}{|l|}
\hline To cite: Ghadban R, \\
Enezate T, Payne J, \\
et al. Heart Asia \\
2019;11:e011142. \\
doi:10.1136/ \\
heartasia-2018-011142 \\
\hline
\end{tabular}

ABSTRACT

Background Morphine is widely used for pain control in patients with acute coronary syndrome (ACS). Several studies have questioned the safety of morphine in this setting with a concern of interaction with and reduced efficacy of antiplatelet agents.

Objective This study aims to systematically review the safety of morphine use in ACS.

Methods MEDLINE, EMBASE and the Cochrane Central Register of Controlled Trials were queried from inception through April 2018. Studies comparing morphine to nonmorphine use in ACS were included. Study endpoints included: in-hospital myocardial infarction (MI), all-cause mortality, stroke, major bleeding, minor bleeding and dyspnoea.

Results A total of 64323 patients with ACS were included from eight studies, seven of which were observational studies and one was a randomised controlled trial. The use of morphine was associated with increased risk of in-hospital recurrent $\mathrm{MI}(\mathrm{OR}$ $1.30,95 \% \mathrm{Cl} 1.18$ to $1.43, \mathrm{p}<0.00001)$. There was, however, no significant difference in terms of all-cause mortality (OR $0.87,95 \% \mathrm{Cl} 0.62$ to $1.22, \mathrm{p}=0.44)$, stroke (OR $0.81,95 \% \mathrm{Cl} 0.39$ to $1.66, \mathrm{p}=0.57$ ), major bleeding (OR $0.49,95 \% \mathrm{Cl} 0.24$ to $1.00, \mathrm{p}=0.05$ ), minor bleeding (OR $0.98,95 \% \mathrm{Cl} 0.41$ to $2.34, \mathrm{p}=$ 0.97 ), or dyspnoea (OR $0.55,95 \% \mathrm{Cl} 0.16$ to $1.83, \mathrm{p}=$ 0.33).

Conclusion The use of morphine for pain control in ACS was associated with an increased risk of inhospital recurrent MI. Randomised clinical trials are needed to further investigate the safety of morphine in ACS.

\section{INTRODUCTION}

The administration of morphine is widely accepted as a treatment for chest pain in the setting of an acute coronary syndrome (ACS). Its use is recommended based on assumptions that adequate pain control modulates sympathetic nervous system activation and therefore decreasing myocardial oxygen demand. ${ }^{2}$ In a large retrospective cohort study, in-hospital complications and 1-year mortality were unaffected by prehospital morphine use in patients with ST elevation myocardial infarction (STEMI), implicating its safety in this patient population. ${ }^{2}$ However, there have been several studies questioning the safety of morphine use in patients with ACS citing delayed and decreased efficacy of antiplatelet agents. ${ }^{23}$ Because of this discrepancy in the literature, we sought to systematically review the safety of morphine use in ACS.

\section{Key messages}

What is already known about this subject?

- Morphine use is recommended by the guidelines for pain management in patients presenting with acute coronary syndromes (ACSs).

What does this study add?

- This study shows that morphine use for pain management in the setting of the ACS was associated with an increased risk of recurrent myocardial infarction and therefore raises a safety concern in this setting.

How might this impact on clinical practice?

- The results of this study suggest that cautious use of morphine, based on case-to-case assessment, should be encouraged until further results from randomised studies are available. It also suggests that some oral antiplatelet agents are less affected by the use of morphine.

\section{METHODS}

The present meta-analysis is performed and reported using the recommendations by Cochrane Collaboration and Preferred Reported Items for Systematic Reviews and Meta-analyses statement. ${ }^{4}$

\section{Endpoints and definitions}

Study endpoints included recurrent myocardial infarction (MI), all-cause mortality, stroke, major bleeding, minor bleeding and dyspnoea. STEMI and non-ST elevation MI (NSTEMI) were defined as ECG changes (persistent ST elevation of $>0.5-1$ $\mathrm{mm}$, new pathological $\mathrm{Q}$ waves or presumed new left bundle branch block for STEMI, or ST depression or $\mathrm{T}$ wave inversion for NSTEMI) with/ without elevated biomarkers (troponin I, T and/ or creatine kinase $\mathrm{MB}$ ) in the appropriate clinical setting of chest pain and/or angina equivalent. ${ }^{25}$ Bleeding was classified into minor or major based on Thrombolysis in Myocardial Infarction (TIMI)

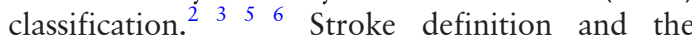
methods of dyspnoea evaluation were not specified in the included studies. All endpoints were reported during the index hospitalisation except one (Bonin et al) which reported endpoints at 1 year.

\section{Information sources and search methods}

Electronic databases of MEDLINE ${ }^{\mathrm{TM}}$, EMBASE and the Cochrane Central Register of Controlled Trials were searched from inception through April 2018 using keyword searches for articles pertaining 


\section{Original research}

Table 1 Patients' baseline characteristics and study description

\begin{tabular}{|c|c|c|c|c|c|c|c|c|c|c|c|c|c|}
\hline Study* & Year & Antiplatelet & ACS type & Treatment & $\begin{array}{l}\text { Morphine } \\
\text { dosing }\end{array}$ & Group & $\begin{array}{l}\text { Patient } \\
\text { number }\end{array}$ & $\begin{array}{l}\text { Age } \\
\text { (year) }\end{array}$ & Male $\%$ & $\begin{array}{l}\text { MI history } \\
\%\end{array}$ & DM \% & HTN \% & $\begin{array}{l}\text { Smoking } \\
\%\end{array}$ \\
\hline \multirow[t]{2}{*}{ Meine et $a l^{10}$} & \multirow[t]{2}{*}{2005} & \multirow[t]{2}{*}{ Clopidogrel (40\%) } & \multirow[t]{2}{*}{ NSTEMI } & \multirow{2}{*}{$\begin{array}{l}66 \% \text { had early } \\
\text { angiogram }\end{array}$} & \multirow{2}{*}{$\begin{array}{l}\text { Intravenous } \\
\text { on } \\
\text { presentation }\end{array}$} & Morphine & 17003 & 65 & 62 & 33 & 32 & 67 & 33 \\
\hline & & & & & & $\begin{array}{l}\text { No } \\
\text { morphine }\end{array}$ & 40036 & 70 & 59 & 31 & 33 & 70 & 25 \\
\hline \multirow[t]{2}{*}{ Puymirat et a ${ }^{2}$} & \multirow[t]{2}{*}{2016} & \multirow[t]{2}{*}{ Clopidogrel (100\%) } & \multirow[t]{2}{*}{ STEMI } & \multirow[t]{2}{*}{$\mathrm{PCl}$} & \multirow{2}{*}{$\begin{array}{l}\text { Intravenous } \\
\text { on } \\
\text { presentation }\end{array}$} & Morphine & 453 & 59 & 81 & 11 & 12 & 39 & 53 \\
\hline & & & & & & $\begin{array}{l}\text { No } \\
\text { morphine }\end{array}$ & 1985 & 64 & 73 & 11 & 17 & 50 & 38 \\
\hline \multirow[t]{2}{*}{ Kubica et $a l^{5}$} & \multirow[t]{2}{*}{2016} & \multirow[t]{2}{*}{ Ticagrelor (100\%) } & \multirow{2}{*}{$\begin{array}{l}\text { STEMI and } \\
\text { NSTEMI }\end{array}$} & \multirow[t]{2}{*}{$\mathrm{PCl}$} & \multirow{2}{*}{$\begin{array}{l}\text { Intravenous } \\
\text { on } \\
\text { presentation }\end{array}$} & Morphine & 35 & 61 & 66 & 14 & 23 & 43 & 55 \\
\hline & & & & & & $\begin{array}{l}\text { No } \\
\text { morphine }\end{array}$ & 35 & 63 & 80 & 23 & 14 & 60 & 45 \\
\hline \multirow[t]{2}{*}{ Parodi et $a l^{6}$} & \multirow[t]{2}{*}{2015} & \multirow{2}{*}{$\begin{array}{l}\text { Ticagrelor }(68 \%) \\
\text { and prasugrel } \\
(32 \%)\end{array}$} & \multirow[t]{2}{*}{ STEMI } & \multirow[t]{2}{*}{$\mathrm{PCl}$} & \multirow[t]{2}{*}{ Not specified } & Morphine & 205 & 62 & 73 & 9 & 53 & 49 & 57 \\
\hline & & & & & & $\begin{array}{l}\text { No } \\
\text { morphine }\end{array}$ & 95 & 61 & 79 & 7 & 15 & 54 & 53 \\
\hline \multirow[t]{2}{*}{ Bellandi et $a l^{3}$} & \multirow[t]{2}{*}{2016} & \multirow{2}{*}{$\begin{array}{l}\text { Ticagrelor }(72 \%) \\
\text { and prasugrel } \\
(28 \%)\end{array}$} & \multirow[t]{2}{*}{ STEMI } & \multirow[t]{2}{*}{$\mathrm{PCl}$} & \multirow[t]{2}{*}{ Not specified } & Morphine & 108 & 64 & 73 & 8 & 45 & 55 & 49 \\
\hline & & & & & & $\begin{array}{l}\text { No } \\
\text { morphine }\end{array}$ & 74 & 64 & 76 & 8 & 16 & 66 & 45 \\
\hline \multirow{2}{*}{$\begin{array}{l}\text { Mccarthy } \\
\text { et } a l^{9}\end{array}$} & \multirow[t]{2}{*}{2017} & \multirow{2}{*}{$\begin{array}{l}\text { Clopidogrel }(77 \%) \\
\text { and ticagrelor } \\
(18 \%)\end{array}$} & \multirow{2}{*}{$\begin{array}{l}\text { STEMI and } \\
\text { NSTEMI }\end{array}$} & $\mathrm{PCl}$ & Not specified & Morphine & 783 & 62 & 76 & 31 & 28 & 68 & 30 \\
\hline & & & & & & $\begin{array}{l}\text { No } \\
\text { morphine }\end{array}$ & 2244 & 65 & 74 & 24 & 23 & 66 & 24 \\
\hline Bonin et $a l^{7}$ & 2018 & Not specified & STEMI & $\mathrm{PCl}$ & Not specified & Morphine & 554 & 59 & 82 & 6 & 13 & 38 & 43 \\
\hline & & & & & & $\begin{array}{l}\text { No } \\
\text { morphine }\end{array}$ & 413 & 61 & 82 & 5 & 13 & 37 & 41 \\
\hline Farag et $a l^{8}$ & 2018 & Clopidogrel (86\%) & STEMI & $\mathrm{PCl}$ & Intravenous & Morphine & 218 & 64 & 78 & 11 & 16 & 49 & 34 \\
\hline & & $\begin{array}{l}\text { and ticagrelor } \\
(14 \%)\end{array}$ & & & prehospital & $\begin{array}{l}\text { No } \\
\text { morphine }\end{array}$ & 82 & 63 & 80 & 12 & 22 & 54 & 29 \\
\hline
\end{tabular}

${ }^{*}$ All study reported in-hospital outcomes except Bonin et al.

ACS, acute coronary syndrome; NSTEMI, non-ST elevation myocardial infarction; PCI, percutaneous coronary intervention; STEMI, ST elevation myocardial infarction

to the use of morphine in ACSs or MI. The search was limited to English-language literature. All randomised, prospective or retrospective studies, and double-arm studies that compared morphine with nonmorphine use in the setting of ACS and at least partially captured endpoints of interest were reviewed. Single-arm studies, studies evaluating stable CAD and studies that used any narcotic agent other than morphine were excluded. Bibliographical references of identified studies and review articles were reviewed in order to find studies that meet our inclusion criteria that were not identified by the initial electronic search.

\section{Data collection and extraction}

Data were extracted independently by two reviewers (RG and TE) based on prespecified components. One of the review authors verified extracted data which included patients' demographics and baseline characteristics, study design, size and event rates of each endpoint (table 1$).^{235-10}$

\section{Risk of bias assessment and data quality}

Two reviewers (RG and TE) independently assessed the quality of each study by examining the risk of bias tool components using the Cochrane risk of bias tool ${ }^{11}$ and Newcastle-Ottawa Scale. ${ }^{12}$ This tool tests for risk of several types of biases based on authors' judgement. The risk of bias is classified to low, intermediate, or high for each type of bias for each study.

\section{Statistical analysis and data synthesis}

Odd ratio (OR) was calculated using the inverse variance method for each study endpoints to allow for pooling of similar

\begin{tabular}{|c|c|c|c|c|c|c|c|c|}
\hline \multirow[b]{2}{*}{ Study or Subgroup } & \multicolumn{2}{|c|}{ Morphine } & \multicolumn{2}{|c|}{ No Morphine } & \multicolumn{2}{|r|}{ Odds Ratio } & \multirow{2}{*}{\multicolumn{2}{|c|}{$\begin{array}{c}\text { Odds Ratio } \\
\text { IV, Random, } 95 \% \mathrm{Cl}\end{array}$}} \\
\hline & Events & Total & Events & Total & Weight & IV, Random, $95 \% \mathrm{Cl}$ & & \\
\hline Bellandi & 1 & 74 & 1 & 108 & $0.1 \%$ & $1.47[0.09,23.81]$ & $\longrightarrow$ & \\
\hline Bonin & 21 & 554 & 7 & 413 & $1.2 \%$ & $2.29[0.96,5.43]$ & & \\
\hline Farag & 3 & 218 & 0 & 82 & $0.1 \%$ & $2.68[0.14,52.45]$ & & \\
\hline Kubica & 1 & 36 & 1 & 36 & $0.1 \%$ & $1.00[0.06,16.63]$ & & \\
\hline McCarthy & 0 & 783 & 0 & 2244 & & Not estimable & & \\
\hline Meine & 646 & 17003 & 1201 & 40036 & $97.1 \%$ & $1.28[1.16,1.41]$ & & \\
\hline Parodi & 1 & 95 & 1 & 205 & $0.1 \%$ & $2.17[0.13,35.07]$ & & \\
\hline Puymirat & 8 & 453 & 14 & 1985 & $1.2 \%$ & $2.53[1.06,6.07]$ & & \\
\hline Total $(95 \% \mathrm{Cl})$ & & 19216 & & 45109 & $100.0 \%$ & $1.30[1.18,1.43]$ & & $\downarrow$ \\
\hline Total events & 681 & & 1225 & & & & & \\
\hline $\begin{array}{l}\text { Heterogeneity: Tau } \\
\text { Test for overall effec }\end{array}$ & $\begin{array}{l}0.00 ; \text { Chi } \\
z=5.34\end{array}$ & $\begin{array}{l}P^{2}=4.39 \\
P=0.00\end{array}$ & $\begin{array}{l}d f=6(P \\
001)\end{array}$ & $=0.62) ;$ & $P^{2}=0 \%$ & & $\begin{array}{l}1 \\
0.01 \quad \text { Favours [Morphine] }\end{array}$ & Favours [No Morphine] \\
\hline
\end{tabular}

Figure 1 Forest plot of recurrent MI: the measure of the effect of morphine versus nonmorphine on in-hospital recurrent MI in each study was plotted using OR and $95 \% \mathrm{Cl}$. The overall results indicate higher $\mathrm{Ml}$ in the morphine group. Ml, myocardial infarction. 


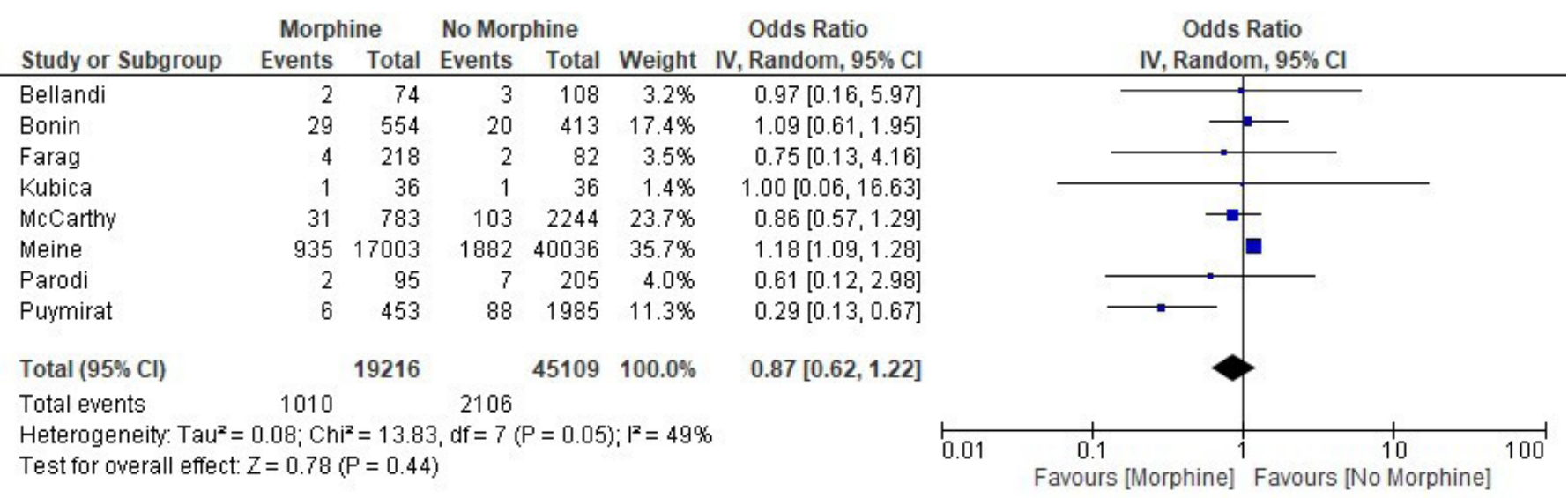

Figure 2 Forest plot of all-cause mortality: the measure of the effect of morphine versus nonmorphine on all-cause mortality in each study was plotted using OR and $95 \% \mathrm{Cl}$. The overall results indicate no significant difference between both groups.

endpoints. Using a random effects model, the average effects for the endpoints and $95 \%$ confidence intervals (CI)s were reported as described by DerSimonian. The $\mathrm{I}^{2}$ statistic was used to assess the heterogeneity of treatment effect across studies that were not attributable to chance or random error. Hence, a value of $50 \%$ or more reflects significant heterogeneity that is due to real differences in study populations, protocols, interventions and/ or endpoints. ${ }^{12}$

The $\mathrm{p}$ value threshold for statistical significance was set at 0.05 for effect sizes. Analyses were conducted using features on RevMan V.5.3.5 (The Nordic Cochrane Centre, Copenhagen, Denmark). The number needed to harm (NNH) was calculated whenever there was a statistically significant difference between morphine and nonmorphine groups using this formula: $\mathrm{NNH}=1 /(\mathrm{MI}$ rate in morphine group $-\mathrm{MI}$ rate in the nonmorphine group). ${ }^{13}$

\section{Methods for including zero events in both arms}

In the case of zero events for an endpoint in both arms of an included study, a continuity factor of 1 was utilised and added to each arm in order to avoid computational errors. Studies reporting no endpoints were not included in the analysis. ${ }^{14}$

\section{RESULTS}

In all, 539 publications were initially identified. After excluding duplicate titles, 473 publications were reviewed yielding eight original articles that met the inclusion criteria and were included in the analysis (online supplementary figure S1). All studies were published in peer-reviewed journals between 2005 and 2018. Seven studies were observational (five retrospective and two prospective) and one was a randomised controlled trial. ${ }^{2} 3$ 5-10 There was a total of 64323 patients (mean age 63.7 years, 73.6\% were male), 19215 patients in the morphine arm and 45108 patients in the nonmorphine arm. Five studies examined patients with STEMI exclusively, another study included NSTEMI exclusively, one included both NSTEMI and STEMI, and only one included all ACS spectrum including unstable angina. Patients with STEMI accounted for $6.6 \%$ of the total population. While different antiplatelet agents were evaluated in the included studies, clopidogrel was used in almost half of the total study population.

Regarding population baseline characteristics, two studies showed a significant difference in TIMI flow prior to PCI, being less favourable in the morphine groups. ${ }^{38}$ In the three largest studies, patients who received morphine were generally younger and more often had a history of coronary artery disease (CAD) and smoking. Additionally, these patients were less sick on presentation, as evidenced by lower Grace Scores and Killip classification, yet were more likely to receive medical therapy for ACS including antiplatelet therapy, anticoagulation, as well as revascularisation ${ }^{2910}$ (table 1)

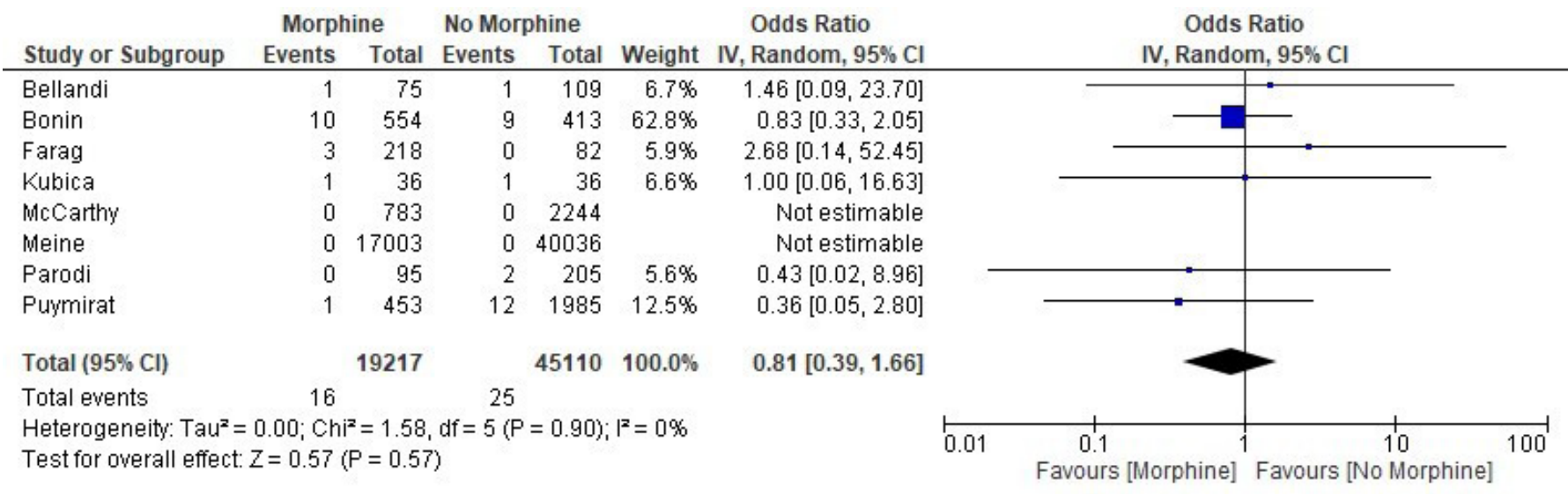

Figure 3 Forest plot of stoke: the measure of the effect of morphine versus nonmorphine on stroke in each study was plotted using OR and 95\% Cl. The overall results indicate no significant difference between both groups. 


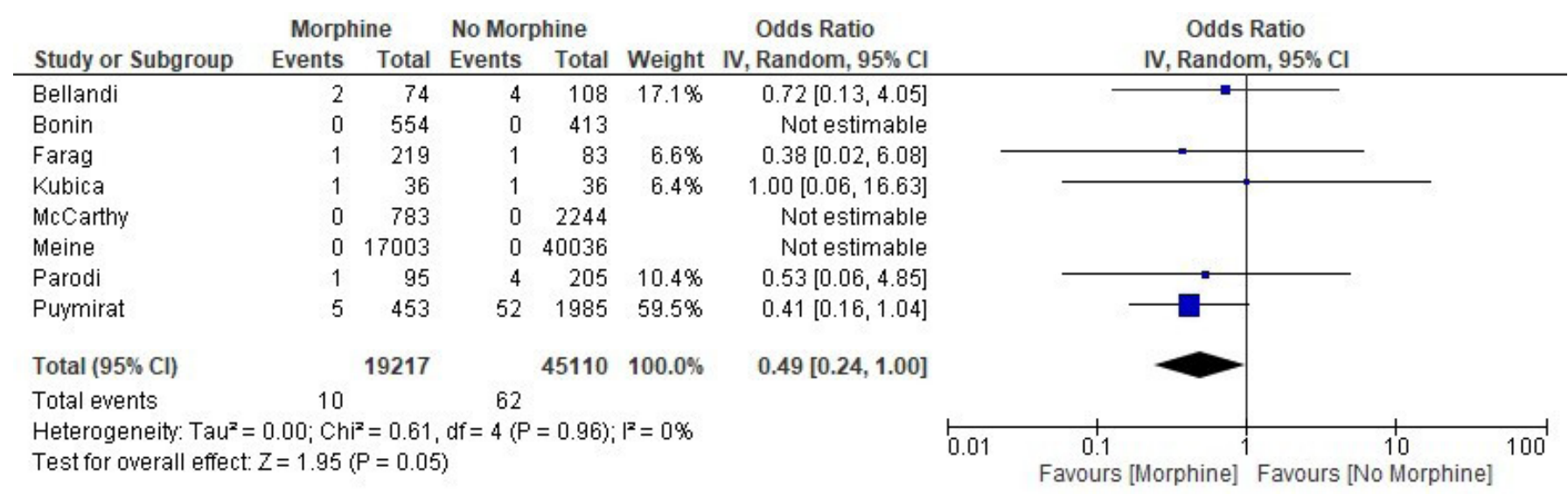

Figure 4 Forest plot of major bleeding: the measure of the effect of morphine versus nonmorphine on major bleeding in each study was plotted using $\mathrm{OR}$ and $95 \% \mathrm{Cl}$. The overall results indicate no significant difference between both groups.

Seven studies reported the incidence of recurrent MI, which was higher with use of morphine $(3.7 \%$ vs $2.9 \%$, OR $1.30,95 \%$ CI 1.18 to $1.43, \mathrm{p}<0.00001$, figure 1$)$. The $\mathrm{NNH}$ was 125 . All studies reported all-cause mortality, six of the eight studies reported stroke, five reported major and minor bleeding, and three studies reported dyspnoea. There was no significant difference in all-cause mortality $(5.6 \%$ vs $4.7 \%$, OR $0.87,95 \% \mathrm{CI}$ 0.62 to $1.22, \mathrm{p}=0.44$, figure 2$)$, stroke $(1.1 \%$ vs $0.9 \%$, OR 0.81 , $95 \%$ CI 0.39 to $1.66, \mathrm{p}=0.57$, figure 3$)$, major bleeding $(1.1 \%$ vs $2.6 \%$, OR $0.49,95 \%$ CI 0.24 to $1.00, p=0.05$, figure 4$)$, minor bleeding $(3.1 \%$ vs $3.2 \%$, OR $0.98,95 \%$ CI 0.41 to 2.34 , $\mathrm{p}=0.97$, figure 5$)$ or dyspnoea $(2.0 \%$ vs $3.7 \%$, OR $0.55,95 \%$ CI 0.16 to $1.83, \mathrm{p}=0.33$, figure 6 ).

\section{Other analyses}

The random effects method was chosen as a primary analysis because of its conservative summary estimate and taking into consideration the between- and the within-study variance. When the analysis was repeated using the fixed effect method, the results remained unchanged except for all-cause mortality which became significantly higher in the morphine group.

Sensitivity analyses were performed to assess the effects of selected measures of studies' design on the pooled effect of morphine on ACS endpoints. This influence was estimated by performing a subgroup analysis and test for subgroup differences. A subanalysis was first performed after excluding the clopidogrel studies and showed that the risk of recurrent MI became similar in both groups. Other subgroup analyses were conducted after excluding the largest population study, then after excluding the one study that reported the endpoints at one year, and finally on STEMI-only studies. The resultsremained unchanged from the overall primary analysis.

Bias-riskassessment

There was intermediate to high riskof bias in regards to population matching in two studies, and unknown risk of biasin regards to similarity of intervention in the morphine arm (i.e. dosing of morphine) in four studies. Otherwise there was no evidence of high risk bias in regards to population selection, exposure assessment, presence of the outcomes of interest at the beginning of the study, independency of outcomes assessment and adequate follow up (Supplemental Table S1 and S2). Funnel test showed symmetrical distribution of the studies indicating low risk of publication (supplemental Figure S2).

Discussion

\section{RISK OF BIAS}

\section{DISCUSSION}

This analysis shows an increased risk of recurrent $\mathrm{MI}$ in patients who had received morphine on presentation for pain control in ACS, regardless type of ACS on presentation (ie, STEMI or NSTEMI). Morphine is associated with decreased absorption of

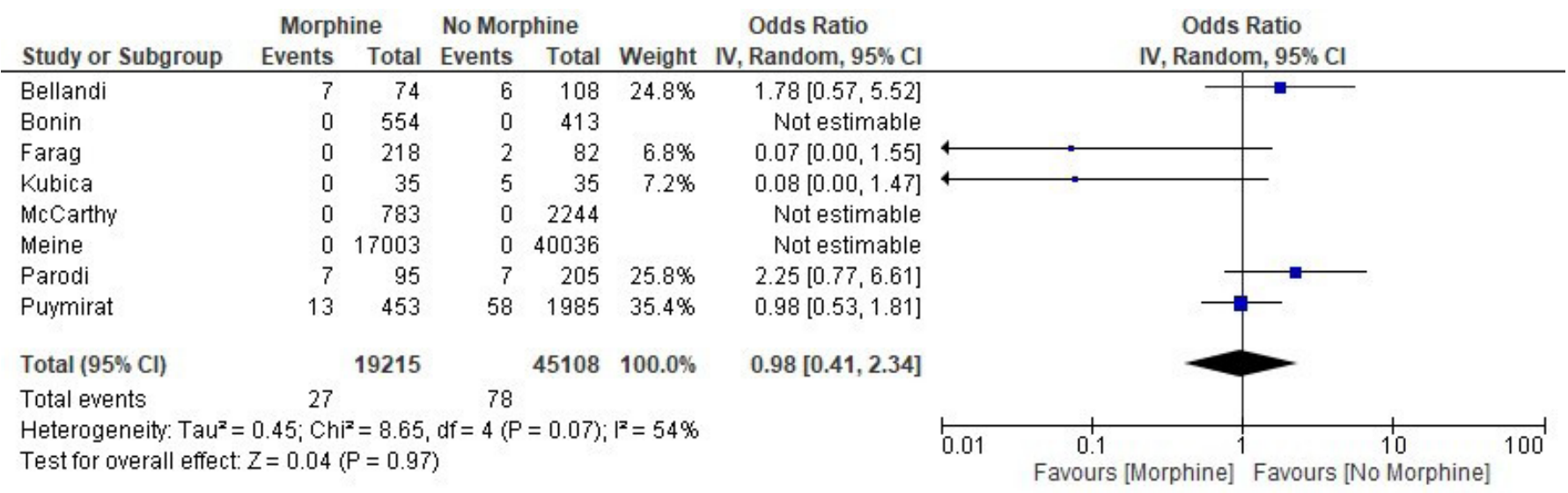

Figure 5 Forest plot of minor bleeding: the measure of the effect of morphine versus nonmorphine on minor bleeding in each study was plotted using OR and $95 \% \mathrm{Cl}$. The overall results indicate no significant difference between both groups. 


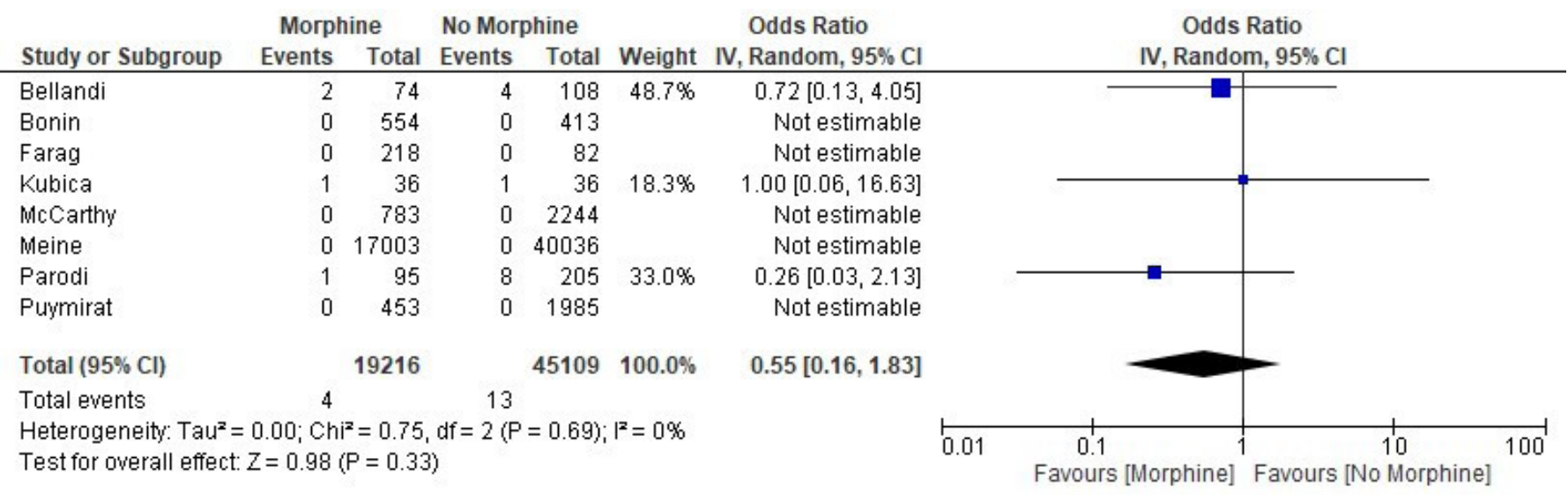

Figure 6 Forest plot of dyspnoea: the measure of the effect of morphine versus nonmorphine on dyspnoea in each study was plotted using OR and $95 \% \mathrm{Cl}$. The overall results indicate no significant difference between both groups.

antiplatelet agents, delayed maximal effect of these medications and poorer myocardial reperfusion manifested as lower prepercutaneous cronary intervention TIMI flow. ${ }^{6}$ Proposed mechanisms have included inhibition of gastrointestinal motility and gastric emptying with induction of emesis, leading to reduced absorption of P2Y12 antiplatelet medications, and thus delayed and reduced efficacy of clopidogrel. ${ }^{3515}$ Additionally, morphine can cause hypotension and bradycardia potentially leading to decreased coronary perfusion. ${ }^{3}$

Newer antiplatelet agents, ticagrelor and prasugrel, are less affected by this action, presumably due to their higher potency. While serum concentrations of these medications have been shown to be reduced with morphine administration, recurrent MI rates were not higher. ${ }^{51415}$ Subgroup analysis of this study, which was performed on studies that mainly used ticagrelor or prasugrel, shows that MI rates were similar in both groups corroborating this observation. Furthermore, patients who had received glycoprotein IIa/IIIb inhibitors had no difference in prepercutaneous coronary intervention TIMI flow or peak troponin presumably because the addition of these intravenous antiplatelets overcomes the effect of morphine on the absorption and efficacy of clopidogrel. ${ }^{8}$

Whether or not the results of this analysis provide some explanation for the negative results of previous upstream P2Y12 inhibitors trials, it is hard to assess as the use of morphine in these trials was not specified. ${ }^{16}{ }^{17}$ However, subgroup analysis of a previous trial showed that prehospital ticagrelor was not associated with improved endpoints except in the subgroup that did not receive morphine in which the ST-segment elevation was significantly improved. ${ }^{18}$ This observation suggests a possible interaction between these antiplatelets and morphine that might decrease the efficacy of these agents.

Despite an increased risk of recurrent MI with the administration of morphine, an increased risk of mortality was not observed. This could be due to the utilisation of early standard treatment for ACS and revascularisation while in-patient, and the longer-term postdischarge outcomes were not available. Furthermore, most of the included studies of this analysis were not powered to detect a difference in mortality. ${ }^{35-9}$

In-hospital bleeding and stroke (both haemorrhagic and ischaemic) rates were similar in the morphine and nonmorphine groups as expected. It was somewhat surprising that dyspnoea was the same in both groups. The most likely explanation is that the standard treatment of ACS has much more of a measurable impact on this anginal equivalent, making it difficult to isolate the effect of morphine alone. Moreover, dyspnoea is a subjective outcome which makes it difficult to assess.

Although the NNH of 125 might be relatively high, it raises important safety concerns given the high incidence of ACS and widespread use of morphine which translate into a notable absolute number of events. The results of this study suggest that cautious use of morphine, based on case-to-case assessment, should be encouraged until further results from randomised studies are available, keeping in mind that the guidelines recommendations regarding the use of morphine in ACS are mainly based on expert opinion rather than randomised clinical trials, and the use of other guidelines-directed antianginal medications that have better safety profile, such as nitrates, might be preferred over the morphine for pain management in ACS. ${ }^{1}$ To our knowledge, this is the first study to systematically review the effect of morphine use in ACS. It raises important safety concerns of morphine use for pain management in ACS possibly because of drug interaction with antiplatelets. It also shows that some oral antiplatelet agents are less affected by this interaction with morphine which makes them preferred agents if morphine been administered.

\section{Study limitations}

This study includes mainly observational studies. Additionally, heterogeneity between and within the studies is an important but unavoidable confounding factor. This includes study design (which was not powered to assess clinical outcomes), size, type of ACS, patient characteristics, severity of illness, treatment modality used for ACS management (invasive vs noninvasive), dosing, and timing of morphine and antiplatelet medications used, which could all have confounding effects on the outcomes associated with morphine administration. Furthermore, the included studies did not specify the type of the recurrent MI, type 1 versus type 4 a.

\section{CONCLUSION}

This study suggests that morphine use in ACS settings was associated with increased risk of in-hospital recurrent MI. Randomised clinical trials are needed to evaluate the safety of morphine in ACS and to determine the preferred antiplatelet regimen when morphine is used. Until then, prudent use, based on a case-bycase clinical assessment, should be encouraged.

Contributors RG: conception, study design, data collection and interpretation, drafting and editing the manuscript, and final approval. TE: conception, study 
design, data collection and interpretation, statistical analysis, drafting and editing the manuscript, and final approval. JP: conception, study design, data collection interpretation, drafting and editing the manuscript, and final approval. HA: data collection and interpretation, drafting and editing the manuscript, and final approval. AH: data collection and interpretation, drafting and editing the manuscript, and final approval. HKF: data collection and interpretation, drafting and editing the manuscript, and final approval. OA: data collection and interpretation, drafting and editing the manuscript, and final approval. KA: revising the manuscript, critical editing and final approval.

Funding The authors have not declared a specific grant for this research from any funding agency in the public, commercial or not-for-profit sectors.

\section{Competing interests None declared.}

Patient consent for publication Not required.

Provenance and peer review Not commissioned; externally peer reviewed.

Open access This is an open access article distributed in accordance with the Creative Commons Attribution Non Commercial (CC BY-NC 4.0) license, which permits others to distribute, remix, adapt, build upon this work non-commercially, and license their derivative works on different terms, provided the original work is properly cited, appropriate credit is given, any changes made indicated, and the use is non-commercial. See: http://creativecommons.org/licenses/by-nc/4.0/.

\section{REFERENCES}

1. O'Gara PT, Kushner FG, Ascheim DD, et al. 2013 ACCF/AHA guideline for the management of ST-elevation myocardial infarction: a report of the American College of cardiology Foundation/American Heart Association Task Force on practice guidelines. Circulation 2013;127:e362-425.

2. Puymirat E, Lamhaut L, Bonnet N, et al. Correlates of pre-hospital morphine use in STelevation myocardial infarction patients and its association with in-hospital outcomes and long-term mortality: the FAST-MI (French Registry of acute ST-elevation and non-ST-elevation myocardial infarction) programme. Eur Heart J 2016;37:1063-71.

3. Bellandi B, Zocchi C, Xanthopoulou I, et al. Morphine use and myocardial reperfusion in patients with acute myocardial infarction treated with primary PCI. Int I Cardiol 2016;221:567-71.
4. Higgins JPT, Thompson SG, Deeks JJ, et al. Measuring inconsistency in meta-analyses. BMJ 2003;327:557-60.

5. Kubica J, Adamski P, Ostrowska M, et al. Morphine delays and attenuates ticagrelor exposure and action in patients with myocardial infarction: The randomized, doubleblind, placebo-controlled impression trial. Eur Heart J 2016;37:245-52.

6. Parodi G, Bellandi B, Xanthopoulou I, et al. Morphine is associated with a delayed activity of oral antiplatelet agents in patients with ST-elevation acute myocardial infarction undergoing primary percutaneous coronary intervention. Circ Cardiovasc Interv 2015;8. doi:10.1161/CIRCINTERVENTIONS.114.001593. [Epub ahead of print: 31 Dec 2014].

7. Bonin M, Mewton N, Roubille F, et al. Effect and safety of morphine use in acute anterior ST-segment elevation myocardial infarction. J Am Heart Assoc 2018;7. doi:10.1161/JAHA.117.006833. [Epub ahead of print: 10 Feb 2018].

8. Farag M, Spinthakis N, Srinivasan M, et al. Morphine analgesia Pre-PPCl is associated with prothrombotic state, reduced spontaneous reperfusion and greater infarct size. Thromb Haemost 2018;118:601-12.

9. $\mathrm{McCarthy} \mathrm{CP}$, Bhambhani V, Pomerantsev E, et al. In-hospital outcomes in invasively managed acute myocardial infarction patients who receive morphine. J Interv Cardiol 2018:31:150-8.

10. Meine TJ, Roe MT, Chen AY, et al. Association of intravenous morphine use and outcomes in acute coronary syndromes: results from the crusade quality improvement initiative. Am Heart J 2005;149:1043-9.

11. Wells BS, D GA, O'Connell JP, et al. The Newcastle-Ottawa scale (NOS) for assessing the quality of nonrandomized studies in meta-analysis 2012

12. Cheng J, Pullenayegum E, Marshall JK, et al. Impact of including or excluding botharmed zero-event studies on using standard meta-analysis methods for rare event outcome: a simulation study. BMJ Open 2016;6:e010983.

13. Suissa S. Calculation of number needed to treat. N Engl J Med 2009:361:424-5.

14. Ganz W. The thrombolysis in myocardial infarction (TIMI) trial. N Eng/ J Med 1985;313.

15. Holzer P. Opioid receptors in the gastrointestinal tract. Regul Pept 2009;155:11-17.

16. Steinhubl SR, Berger PB, Mann JT, et al. Early and sustained dual oral antiplatelet therapy following percutaneous coronary intervention: a randomized controlled trial. JAMA 2002;288:2411-20.

17. Montalescot G, Bolognese L, Dudek $\mathrm{D}$, et al. Pretreatment with prasugrel in non-STsegment elevation acute coronary syndromes. N Engl J Med 2013;369:999-1010.

18. Montalescot G, van 't Hof AW, Lapostolle F, et al. Prehospital ticagrelor in ST-segment elevation myocardial infarction. N Engl J Med 2014;371:1016-27. 